\title{
Correlates of Low-Fat Milk Consumption in a Multi-Ethnic Population
}

\author{
Christine Maglione, Jodi Barnett, and Jay E. Maddock \\ University of Hawaii at Manoa
}

\begin{abstract}
Objective: To assess the correlates of low-fat milk consumption in a multi-ethnic population. Design: Cross-sectional random digit dial telephone survey of adults residing in Hawaii. Setting \& Participants: The survey was completed by 600 adults who consumed cow's milk. Five ethnicities composed over $86 \%$ of the sample: Caucasian (36\%), Hawaiian (17\%), Japanese (18\%), Filipino (10\%), and Chinese (5\%). The average age of participant was $45.6 .84 \%$ had completed high school and 35\% had completed college. Variables Measured: All variables were self-reported. Type of milk consumed (high-fat vs. low-fat) was the dependent variable. Independent variables included age, gender, ethnicity, body mass, attitude, normative beliefs, and stage of change. Analysis: Chi-squares and logistic regression were used for the analysis $(\mathrm{p}<$ .05). Results: Younger and less educated people were less likely to drink low-fat milk, as were Native Hawaiians and Filipinos. In the multivariate analyses only attitudes, normative beliefs, and education were significant predictors. Conclusions and Implications: Attitudes and normative beliefs towards milk consumption explain more of the variance in type of milk consumption than demographic characteristics. This data indicates the feasibility of testing interventions designed to influence attitudes and normative beliefs towards low-fat milk consumption in Asian and Pacific Island communities.
\end{abstract}

(C) 2005 Californian Journal of Health Promotion. All rights reserved. Keywords: nutrition, behavior change, disparate populations

\section{Introduction}

Milk is an excellent source of calcium, vitamins, and protein. Drinking milk is beneficial for the health of your bones, muscles, and teeth (National Osteoporosis Foundation [NOF], 2005). Yet whole and $2 \%$ milk contain a great deal of saturated fat. One cup of whole milk has 8 grams of saturated fat and $2 \%$ milk contains 5 grams of saturated fat (Reger, Wootan, BoothButterfield, \& Smith, 1998; Wootan, 1996). Diets rich in saturated fat are linked to high blood cholesterol, obesity, and heart disease, which contribute to thousands of deaths each year (NOF, 2005; US Department of Agriculture [USDA], 2000). High-fat milk is one of the leading sources of saturated fat in the American diet (Reger et al., 1998). Public health programs aimed at reducing saturated fat consumption have the potential to influence the incidence of heart disease in the US. Switching from high-fat milk ( $2 \%$ or whole) to low-fat milk ( $1 \%$ or skim) is one simple and effective way to reduce the consumption of saturated fat (Reger et al., 1998; USDA, 2000; Wootan, 1996).

Understanding population differences in milk drinking habits is necessary to effectively develop public health programs aimed at reducing saturated fat intake by encouraging individuals to switch from high-fat milk to low-fat milk. Previous studies have reported the milk drinking habits of the elderly (Elbon, Johnson, \& Fischer, 1998), preadolescents and adolescents (Auld, Boushey, Bock, Bruhn, Gabel, Gustafson et al., 2002; Oshiro, Novotny, \& Titchenal, 2003), Australian adults (Bus \& Worsley, 2003), and primarily Caucasian adults (Reger et al., 1998).

Most studies of low-fat milk consumption have focused on white adults, since ethnic 
minority individuals have shown higher levels of lactose intolerance. One multiethnic study reports that lactase nonpersistence occurs in $21 \%$ of whites, $51 \%$ of Hispanics, $75 \%$ of Blacks, $79 \%$ of Native Americans, and $80 \%$ of Asian Americans (Miller, Jarvis, \& McBean, 1997). However, a recent surveillance survey in Hawaii found that two-thirds of multiethnic (mostly Asian-American) adults consumed cows' milk on a regular basis (Maddock, Marshall, Nigg, \& Barnett, 2003). While research reports that gender, age, marital status, number of children, and nutrition knowledge influence the consumption of low-fat milk (Bus et al., 2003; Elbon et al., 1998; Kalliopuska, 1993) there are inconsistent findings regarding the influence of income, education, and ethnic background (Bus et al., 2003; Elbon et al., 1998; Elbon, Johnson, \& Fischer, 1996). Limited information exists relating these factors, as well as milk attitudes and normative beliefs to low-fat milk consumption in a multiethnic population of adults (Raats, Shepherd, \& Sparks, 1993). Further research is warranted to gain a better understanding of ethnic differences in milkfat consumption. Therefore the primary goal of this paper is descriptive - to report the correlates of low-fat milk consumption of a multiethnic population.

\section{Methods}

\section{Data Collection}

A cross-sectional survey was administered to Hawaii's non-institutionalized adult population, using random digit dialing procedures (Waksberg, 1978). Surveys were conducted for three weeks mid May thru June of 2004. The person in the household over 18 with the most recent birthday was interviewed, to provide randomization within each household. Only individuals who consumed cows' milk were included in the study population. The survey took approximately thirty minutes to complete. Experienced interviewers were trained on the study procedures prior to survey administration, instructed on interviewing techniques regarding probing and refusals, and supervised during live telephone calls. The computer aided telephone interview (CATI) system, designed specifically for the survey, controlled for out of range responses, consistency of responses, and appropriate application of skip patterns.

\section{Measures}

The University's Committee on Human Studies approved all research procedures. Informed consent was obtained over the phone. Only adult participants that reported consuming cows' milk were included in the study.

Participants were first asked about their household members, the household milk purchasing and drinking habits, and respondent's milk drinking habits (Reger et al., 1998). Whole, $2 \%$ milk and mixed highfat milk were recoded as high-fat milk. Skim milk, $1 \%$ milk, and mixed low-fat milk were recoded as low-fat milk. Participants who regularly consumed both high and low-fat milk (3.0\%) were excluded from further analyses.

Additional psychosocial measures were also assessed including stage of change from the Transtheoretical Model, and attitudes, and normative beliefs regarding milk consumption from the Theory of Planned Behavior (Montano, \& Kasprzyk, 2002; Prochaska, Redding, \& Evers, 2002). Attitude towards low-fat milk consumption was measured using a 4-item scale (alpha $=$ $.58)$, a three-item scale was used to assess normative beliefs (alpha $=.51$ ), and a one item staging algorithm was used to assess stage of change. The staging algorithm classified respondents into one of the five stages of change: precontemplation, contemplation, preparation, action, or maintenance based on their milk drinking habits over the last six months. The attitude scale included 4 questions that assessed the taste and health benefits of low-fat milk. The normative beliefs scale included 3 questions that asked respondents if they thought the people in their community, their doctor, and their family and friends thought 
that drinking low-fat milk was good. All responses to attitude and normative belief questions were completed on a five point Likert scale that ranged from strongly agree to strongly disagree. Lower scale scores indicate a positive attitude and positive normative beliefs towards low-fat milk consumption. The attitude and normative belief items have been tested and validated in previous studies of milk consumption (Booth-Butterfield \& Reger, 2004). Demographic variables included age, sex, marital status, ethnic identification, perceived health, income level, education attained, height, weight, and zip code.

\section{Analyses}

All data was analyzed using SPSS 11.5. Chisquares and t-tests were used to assess univariate differences in type of milk consumption. Logistical regression analyses were used to assess multivariate predictors of low-fat milk consumption. Predictor variables included age, gender, ethnicity, education, normative beliefs and attitudes. For gender, males were listed as the reference category. For ethnicity, whites were the reference category.

\section{Results}

\section{Participants}

A random sample of 600 residents $(69 \%$ acceptance rate) participated in the study with 595 respondents providing usable data. An additional, 296 residents did not qualify to participate in the study because they did not consume cows' milk. Of the sample, $51 \%$ were male and $49 \%$ were female. Five ethnicities composed over $86 \%$ percent of the sample: white (36\%), Hawaiian (17\%), Japanese (18\%), Filipino (10\%), and Chinese $(5 \%)$. The average age of the participants was 45.6. The education level was high with $84 \%$ completing high school and $35 \%$ completing 4 years of college. The median annual household income was
$\$ 45,000$. A majority of the participants were married (57\%), did not have children living in the household (53.4\%), and lived on the island of Oahu $(72 \%)$.

\section{Milk Consumption}

Approximately two-thirds of the households consumed high-fat milk $(21.8 \%$ whole milk and $45.2 \%-2 \%$ milk). Low-fat milk consumption was low with only $4.0 \%$ consuming $1 \%$ milk and $23.9 \%$ consuming skim milk. The type of milk respondents consumed (high vs. low-fat) differed significantly, with younger, less educated individuals more likely to drink high-fat milk (see Table 1). Filipinos and Native Hawaiians were more likely to drink highfat milk than Japanese and white respondents. A non-significant trend indicated that males were more likely to drink high-fat milk than females. No significant differences were seen by body mass index.

Low-fat milk drinkers $(\mathrm{M}=2.28, \mathrm{sd}=.47)$ had a more positive attitude towards low-fat milk consumption than high-fat milk drinkers $(\mathrm{M}=2.73, \mathrm{sd}=.54, \mathrm{t}(502)=-9.05$, $\mathrm{p}<.001)$. Low-fat milk drinkers $(\mathrm{M}=2.22$, $\mathrm{sd}=.50)$ also had a more positive normative belief than high-fat milk drinkers $(\mathrm{M}=2.65$, $\mathrm{sd}=.62, \mathrm{t}(496)=-7.61, \mathrm{p}<.001)$. Most of the respondents were in the precontemplation $(45.7 \%)$ or maintenance $(38.8 \%)$ stage of change. Few individuals were in the contemplation $(6.7 \%)$, preparation $(3.8 \%)$ or action $(4.7 \%)$ stage of change. Attitude and normative beliefs also changed significantly across the stages of change (see Table 2). Tukey follow-up tests revealed significant differences on the normative beliefs scale only between the precontemplation and maintenance stage. On the attitudes scale, significant differences were seen between precontemplation and contemplation, action and maintenance. 
Table 1

Demographic Variables by Type of Milk Consumption

\begin{tabular}{|l|c|c|c|c|}
\hline & N & $\begin{array}{c}\text { \% Low } \\
\text { Fat Milk }\end{array}$ & $\begin{array}{c}\text { \% High } \\
\text { Fat Milk }\end{array}$ & \\
\hline Age & & & & $\chi^{2}(2)=12.2, \mathrm{p}<.01$ \\
\hline 18 to 34 yrs. & 162 & 22.2 & 77.8 & \\
\hline 35 to 54 yrs. & 225 & 29.3 & 70.7 & \\
\hline $55+$ yrs & 177 & 39.5 & 60.5 & \\
\hline Total & 564 & 30.5 & 69.5 & \\
\hline Ethnicity & & & & $\chi^{2}(3)=16.7, \mathrm{p}<.001$ \\
\hline White & 204 & 34.8 & 65.2 & \\
\hline Native Hawaiian & 99 & 21.2 & 78.8 & \\
\hline Filipino & 55 & 20.0 & 80.0 & \\
\hline Japanese & 104 & 44.2 & 55.8 & \\
\hline Education & & & & $\chi^{2}(3)=17.3, \mathrm{p}<.001$ \\
\hline Less than High School & 85 & 17.6 & 82.4 & \\
\hline High School & 103 & 24.3 & 75.7 & \\
\hline Some College & 185 & 30.8 & 69.2 & \\
\hline Four or more years of College & 204 & 40.2 & 59.8 & \\
\hline Gender & & & & $\chi^{2}(1)=2.9, \mathrm{p}=.09$ \\
\hline Males & 295 & 27.8 & 72.2 & \\
\hline Females & 285 & 34.4 & 65.6 & \\
\hline Body Mass Index & & & & $\chi^{2}(2)=0.3, \mathrm{n} . \mathrm{s}$ \\
\hline Normal Weight & 227 & 30.0 & 70.0 & \\
\hline Overweight & 210 & 31.9 & 68.1 & \\
\hline Obese & 99 & 32.3 & 67.7 & \\
\hline
\end{tabular}

Table 2

Attitude and Normative Beliefs by Stage of Change for Low-Fat Milk

\begin{tabular}{|l|c|c|c|}
\hline \multicolumn{1}{|c|}{ Stage of Change } & N & $\begin{array}{c}\text { Attitude } \\
\text { M (sd) }\end{array}$ & $\begin{array}{c}\text { Normative beliefs } \\
\text { M (sd) }\end{array}$ \\
\hline Precontemplation (PC) & 212 & $2.84(0.53)$ & $2.72(0.63)$ \\
\hline Contemplation (C) & 23 & $2.51(0.51)$ & $2.44(0.58)$ \\
\hline Preparation (P) & 22 & $2.70(0.58)$ & $2.61(0.53)$ \\
\hline Action (A) & 37 & $2.43(0.51)$ & $2.37(0.68)$ \\
\hline Maintenance (M) & 227 & $2.33(0.49)$ & $2.30(0.52)$ \\
\hline \multicolumn{2}{|l|}{} & $\mathrm{F}(4,520)=28.2, \mathrm{p}<.001^{1}$ & $\mathrm{~F}(4,514)=14.9, \mathrm{p}<.001^{2}$ \\
\hline
\end{tabular}

${ }^{2}$ Tukey Post-hoc test, $\mathrm{PC}>\mathrm{M}$

The logistic regression model was significant, $\mathrm{c} 2(8)=93.8, \mathrm{p}<.001$ and correctly predicted the type of milk consumed $72.5 \%$ of the time (original model $=67.6 \%)($ see Table 3$)$. Education, normative beliefs and attitudes were all significant predictors of type of milk consumption. Gender, ethnicity and age were not significant predictors. 
Table 3

Odds Ratios for High-Fat Milk Consumption and Related Variables $(\mathrm{n}=411)$

\begin{tabular}{|l|c|c|}
\hline \multicolumn{1}{|c|}{ Variable } & Odds Ratio & 95\% Confidence Interval \\
\hline Hawaiian ethnicity & 1.29 & $0.68-2.47$ \\
\hline Filipino ethnicity & 1.52 & $0.66-3.50$ \\
\hline Japanese ethnicity & 0.78 & $0.44-1.41$ \\
\hline Female & 0.85 & $0.52-1.37$ \\
\hline Age & 0.99 & $0.98-1.01$ \\
\hline Education & 0.93 & $0.88-0.98$ \\
\hline Normative beliefs & 2.03 & $1.31-3.16$ \\
\hline Attitude & 3.41 & $2.07-5.61$ \\
\hline
\end{tabular}

$\chi^{2}(8)=93.8, p<.001$

\section{Discussion}

Several factors are related to the consumption of low-fat milk. Older and more educated people are more likely to drink high-fat milk as are Japanese and white individuals. While these are important factors, attitudes and normative beliefs showed much stronger relationships to milk type selection in the multivariate analysis. This is encouraging since these factors are more easily influenced compared to more stable demographic characteristics. It is possible that interventions, which target specific attitudes and normative beliefs towards low-fat milk consumption, may be effective in changing milk consumption habits in this population. Social marketing campaigns for low-fat milk have been successful in changing attitudes and normative beliefs and subsequently behavior in white and Latino populations (Reger et al., 1998; Weslcher \& Wernick, 1992). To date, little is known about the effects of these campaigns in Asian and Pacific Island communities. This data indicates the feasibility of testing this approach.

The stage of change analysis revealed that most people are in the stable stages of change (precontemplation and maintenance). However, with almost $15 \%$ of the population having recently made a change or thinking about making a change, interventions targeted towards this group could have significant impact.

A limitation of this study is the use of selfreport telephone surveys. Data accuracy can be affected by social desirability, low response rate and inaccurate recollection of events. These factors are reduced in this study by a good response rate (69\%), low demand item content (milk drinking) and stable behaviors (type of milk consumed).

\section{Implications for Research and Practice}

These findings yield valuable information regarding the demographic and psychosocial characteristics of low-fat milk drinkers. With two-thirds of the adults in this sample drinking high-fat milk, identifying predictors of low-fat milk consumption enable public health professionals to create more effective public health programs designed to promote low-fat milk consumption. Further research is needed regarding the efficacy of different strategies used to change milk drinking habits. 


\section{References}

Auld, G., Boushey, C.J., Bock, M., Bruhn, C., Gabel, K., Gustafson, D., et al. (2002). Perspectives on intake of calcium-rich foods among Asian, Hispanic, and White preadolescent and adolescent females. Journal of Nutrition Education \& Behavior, 34(5), 242-251.

Booth-Butterfield, S., \& Reger, B. (2004). The message changes belief and the rest is theory: the "1\% or less" milk campaign and reasoned action. Preventive Medicine, 39, 581-588.

Bus, A. E., \& Worsley, A. (2003). Consumers' health perceptions of three types of milk: a survey in Australia. Appetite, 40, 93-100.

Centers for Disease Control and Prevention. (2002). The burden of chronic disease and their risk factors national and state perspectives 2002. Retrieved November 21, 2004, from http://www.cdc.gov/nccdphp/burdenbook2002/03nutriadult.htm

Elbon, S. M., Johnson, M. A., \& Fischer, J. G. (1996). Developing an instrument to measure the influence of knowledge, behaviors, and attitudes on milk consumption patterns in older participants of a community wellness group: A pilot study. Journal of Nutrition for the Elderly, 15(4), 21-37.

Elbon, S. M., Johnson, M. A., \& Fischer, J. G. (1998). Milk consumption in older Americans. American Journal of Public Health, 88, 1221-1224.

Kalliopuska, M. (1993). Light milk products: Effects of product information on women participating in the women's ten kilometer run. Perceptual \& Motor Skills, 77, 457-458.

Maddock, J. E., Marshall, C., Nigg, C. R., \& Barnett, J. D. (2003). Development and first year results of a psychosocial surveillance system for chronic disease related health behaviors. Californian Journal of Health Promotion, 1(5), 54-64.

Miller, G. D., Jarvis, J. K., \& McBean, L. D. (1997). Lactose intolerance. In handbook of dairy foods and nutrition. (pp.187-220). Boca Raton, Florida: CRC Press.

Montano, D. E., \& Kasprzyk, D. (2002). The theory of reasoned action and the theory of planned behavior. In K. Glanz, B. K. Rimer \& F. M. Lewis (Eds.), Health Behavior and Health Education, 3rd Edition. (pp. 67-98). San Francisco, CA: Jossey-Bass.

National Osteoporosis Foundation. (2005). Prevention calcium, \& vitamin D. Retrieved November 22, 2004, from http://www.nof.org/prevention/calcium.htm

Oshiro, C. E., Novotny, R., \& Titchenal, C. A. (2003). Calcium intake of Asian and Caucasian adolescents in Hawaii. Hawaii Medical Journal, 62(12), 272-276.

Prochaska, J. O., Redding, C. A., \& Evers, K. E. (2002). The transtheoretical model and stages of change. In K. Glanz, B. K. Rimer \& F. M. Lewis (Eds.), Health Behavior and Health Education, 3rd Edition. (pp. 99-120). San Francisco, CA: Jossey-Bass.

Raats, M. M., Shepherd, R., \& Sparks, P. (1993). Attitudes, obligations, and perceived control: predicting milk selection. Appetite, 20, 239-241.

Reger, B., Wootan, M. G., Booth-Butterfield, S., \& Smith, H. (1998). 1\% or less: a communitybased nutrition campaign. Public Health Reports, 113(5), 410-419.

U. S. Department of Agriculture. (2000). Dietary guidelines for Americans. Retrieved November 22, 2004, from http://www.health.gov/dietaryguidelines/dga2000/DIETGD.PDF

Waksberg, J. (1978). Sampling methods for random digit dialing. Journal of the American Statistical Association, 73, 40-46.

Weslcher, H., \& Wernick, S. M. (1992). A social marketing campaign to promote low-fat milk consumption in an inner-city Latino community. Public Health Reports, 107, 202-207.

Wootan, M. G. (1996). A first step toward healthy eating: The 1\% or less handbook. Washington, DC: Center for Science in the Public Interest. 


\title{
Acknowledgments
}

This study was funded by the Tobacco Settlement Special Fund through a contract with the Hawaii Department of Health as part of the Healthy Hawaii Initiative. Thanks to Katie Richards for assistance in editing the manuscript.

\author{
Author Information \\ Christine Maglione, MA \\ Jodi Barnett, MA \\ Department of Public Health Sciences \\ University of Hawaii at Manoa \\ Jay E. Maddock, Ph.D.* \\ Department of Public Health Sciences \\ University of Hawaii at Manoa \\ 1960 East-West Rd. \\ Honolulu, HI 96822 \\ Ph.: 808-956-5779 \\ E-Mail: jmaddock@hawaii.edu \\ * corresponding author
}

